ISSN: 0213-2087 eISSN: 2444-7080

DOI: http://dx.doi.org/10.14201/shhc20183691116

\title{
LOS DERECHOS HUMANOS COMO MARCO CULTURAL LEGITIMADOR O MOVILIZADOR EN EL MESOFRANQUISMO: EL VIGÉSIMO ANIVERSARIO DE LA DUDH EN CUADERNOS PARA EL DIÁLOGO
}

\section{Human Rights as Legitimizing Cultural Framework or Mobilizing in the Mesofranquism: The Twentieth Anniversary of the DUDH in Cuadernos para el Diálogo}

\author{
María de la Paz PANDO BALLESTEROS \\ Universidad de Salamanca \\ mpaz@usal.es
}

Recepción: 15/05/2018 Revisión: 24/09/2018 Aceptación: 27/09/2018

RESUMEN: En 1968, con motivo de la conmemoración del vigésimo aniversario de la Declaración Universal de los Derechos Humanos, la Revista Cuadernos para el Diálogo, una de las publicaciones más destacadas de la época, editó un número extraordinario, que, bajo pretexto de reflexionar sobre la DUDH, sus consecuencias y resultados lanzaba una crítica al Régimen franquista centrada precisamente en el incumplimiento de dichos derechos.

El interesante número que nos proponemos analizar entra en debates tan importantes como la funcionalidad del discurso de los Derechos Humanos como "marco cultural" potencialmente movilizador contra la dictadura franquista; en el debate en torno a la concepción de los derechos de primera y segunda generación, como derechos individuales o "colectivos", todavía no resuelto y, dado que Cuadernos reivindicaba la Democracia como único sistema posible en el que podían desarrollarse y garantizarse los Derechos Humanos, se incluía una reflexión sobre la misma y el debate hacia qué modelo evolucionar. 

EN EL MESOFRANQUISMO: EL VIGÉSIMO ANIVERSARIO DE LA DUDH EN CUADERNOS...

\author{
Palabras clave: Derechos Humanos; Cuadernos para el Diálogo; Democracia; \\ tardofranquismo
}

SUMMARY: In 1968, on the occasion of the commemoration of the twentieth anniversary of the Universal Declaration of Human Rights, the Journals Notebooks for Dialogue, one of the most outstanding publications of the time, published an extraordinary number, which under the pretext of reflecting on the UDHR, its consequences and results launched a criticism of the Franco regime centered precisely on the breach of these rights.

The interesting number that we propose to analyze enters debates as important as the functionality of the discourse of Human Rights as a "cultural framework" potentially mobilizing against the Franco dictatorship; in the debate around the conception of first and second generation rights, as individual or "collective» rights, still unresolved and, given that Cuadernos claimed Democracy as the only possible system in which human rights could be developed and guaranteed, it included a reflection on it and the debate towards which model to evolve.

Key words: Human Rights: Cuadernos para el Diálogo; Democracy; tardofranquismo.

Con motivo de la conmemoración en 1968 del vigésimo aniversario de la Declaración Universal de los Derechos Humanos (DUDH), la Organización de Naciones Unidas, preocupada por las dificultades halladas desde su misma proclamación para dar carácter jurídicamente vinculante a tales principios ${ }^{1}$, declaró dicho año como «Año Internacional de los Derechos Humanos».

1. Con el fin de superar el carácter apenas declarativo y orientativo que se había logrado dar al DUDH en 1948, la ONU había procedido a la redacción de dos Pactos Internacionales de Derechos Humanos de carácter vinculante: el Pacto Internacional de Derechos Económicos, Sociales y Culturales (PIDESC) y el Pacto Internacional de Derechos Civiles y Políticos (PIDCP), ambos aprobados por unanimidad el 16 de diciembre de 1966 en sesión plenaria de la Asamblea General, tras un largo y difícil proceso de negociaciones. Cada Pacto entraría en vigor, según lo acordado, cuando 35 Estados lo hubieran ratificado o se hubieran adherido a él. El Protocolo Facultativo anexo al Pacto Internacional de Derechos Civiles y Políticos requería solo diez ratificaciones o adhesiones. Ciertamente, a fines de 1967, 19 Estados habían firmado el Pacto de Derechos Económicos, Sociales y Culturales, y 18 el de Derechos Civiles y Políticos, mientras que 8 Estados, por su parte, habían firmado el Protocolo. Sin embargo, la ONU tenía ya 123 estados miembros y hasta el 16 de octubre de 1967 ningún Gobierno había ratificado o se había adherido a ninguno de estos tres instrumentos internacionales, siendo la firma, como es sabido, insuficiente para dar fuerza jurídica alguna los mismos. René Cassin, autor del primer proyecto de Declaración Universal, reconocía abiertamente, tras recoger estos datos, en el número XXI, de enero de 1968, del Correo de la UNESCO titulado 1968. Año Internacional de Derechos Humanos [disponible en <http://unesdoc.unesco.org/images/0007/000782/078234so.pdf> (C.15-04- 2018): «Va a pasar todavía largo tiempo antes de que esos Pactos se vean ratificados por un número suficiente de Estados y puedan entrar en vigencia, a menos que una vigorosa presión de la opinión pública no estimule dentro de cada país la correspondiente ratificación oficial. Tampoco podrá hacerse realidad 
MARÍA DE LA PAZ PANDO BALLESTEROS

LOS DERECHOS HUMANOS COMO MARCO CULTURAL LEGITIMADOR O MOVILIZADOR

EN EL MESOFRANQUISMO: EL VIGÉSIMO ANIVERSARIO DE LA DUDH EN CUADERNOS...

Aprovechando la oportunidad que la adhesión a tal efeméride podría brindar al Régimen franquista para lavar su maltrecha imagen internacional, el Consejo de Ministros español del momento se sumó a la antedicha propuesta en el mes enero de 1968, iniciando, como gesto de buena voluntad, los trámites para la ratificación de la "Convención para la Prevención y la Sanción del Delito de Genocidio» y la "Convención Suplementaria sobre la Abolición de la Esclavitud, la Trata de Esclavos y las Instituciones y Prácticas Análogas a la Esclavitud», en vigor desde abril de 1957, cuyo cumplimiento no parecía representar un compromiso especialmente incómodo para el Estado ${ }^{2}$. La Dictadura, repitiendo la estrategia ya empleada con la OIT, de ofrecer a la comunidad internacional compromisos sectoriales con las causas específicas que juzgaba más fácilmente asumibles ${ }^{3}$, en lugar de ratificar Pactos más exigentes por su dimensión globalizadora y por sus trascedentes implicaciones socio-políticas para el Sistema, se curaba en salud por si acaso se le requiriese, dado que había votado a favor de su aprobación, para ratificar los Pactos Internacionales de 1966 que desarrollaban la DUDH, y que estaban aún huérfanos de adhesiones, los cuales apenas entraron en vigor en 1976. España no los ratificó hasta 1977, ya muerto el Dictador.

El falso interés exhibido tempranamente por los derechos humanos, de momento un ideal no imperativo, por el Régimen de Franco, que había promulgado el 30 de junio de 1945, apenas 4 días después de la firma de la Carta de las Naciones Unidas de San Francisco ${ }^{4}$, el Fuero de los Españoles, un sucedáneo de los mismos, no debe llevarnos a engaño: el franquismo, como el resto de regímenes totalitarios del periodo, no sentían respeto alguno por el incipiente discurso producido al respecto por la ONU, aunque ciertos Estados nada democráticos fingieran, después de la segunda Guerra Mundial, interesarse por dichos valores y asumirlos, resignificando en sus textos jurídicos, o en sus discursos políticos, las palabras que designaban tales derechos, vaciándolas de contenido y desnaturalizándolas 5 . De este

la Carta de Derechos Humanos sin que se hagan esfuerzos continuos para que sus disposiciones se apliquen efectiva y universalmente».

2. Ni dotado del nivel de exigencia que, en las circunstancias actuales, tras la expansión de la trata y el mayor conocimiento de tal lacra, reporta la ratificación, producida en el año 2000, del Protocolo de las Naciones Unidas para Prevenir, Reprimir y Sancionar la Trata de Personas, también conocido como Protocolo de Palermo.

3. Ver al respecto Martínez Quinteiro, M. ${ }^{a}$ Esther: La denuncia del sindicato vertical. Las relaciones entre España y la Organización Internacional del Trabajo (1969-1975). Madrid: CES, 1997.

4. Que entró en vigor el 24 de octubre de 1945

5. Pando Ballesteros, M. ${ }^{a}$ Paz: "Historia de los Derechos Humanos. Del origen a la internacionalización del discursom. En Enríquez Sánchez, José M. ${ }^{\text {; }}$ Masferre, Aniceto; Aguilera Portales, Rafael Enrique: Derechos Humanos. Un análisis multidisciplinar de su teoría y praxis. Madrid: UNED, 2017.

Véase al respecto, en Portugal, la estrategia salazarista de manipulación y tergiversación oportunista del discurso de los derechos humanos, tan descarada como la franquista, aunque más sofisticada y versátil que ella, en la modélica monografía de CARvalHo CAmpina, Ana Cláudia: Antonio de Oliveira Salazar. Discurso político e "retórica» dos direitos humanos. Salamanca: Eds. Universidad de Salamanca, 2013. 
LOS DERECHOS HUMANOS COMO MARCO CULTURAL LEGITIMADOR O MOVILIZADOR EN EL MESOFRANQUISMO: EL VIGÉSIMO ANIVERSARIO DE LA DUDH EN CUADERNOS...

modo operó el Fuero de los Españoles, una sedicente carta de derechos que había sido impulsado por la rama colaboracionista de los democristianos españoles, los nacional católicos, que se esforzaban en maquillar al Régimen para hacerlo internacionalmente más aceptable. Un año antes de la promulgación del Fuero de los españoles, el Vaticano, que nunca llegó a ser miembro de la ONU, había sondeado sin éxito la posibilidad de obtener tal condición ${ }^{6}$, lo que hubiera implicado aceptar las obligaciones de la Carta de la ONU. Para los católicos esto, aunque equívoco, pudo aparecer como una señal de que cabía una reconciliación con los valores proclamados por la ONU, el sueño del filósofo tomista Jacques Maritain, uno de los inspiradores de la Declaración del 1948 y referencia frecuente para los democristianos de Cuadernos. La sensación se reforzó en 1964 cuando el Vaticano logró ser admitido como Estado Observador no Miembro, lo que le aseguraba privilegios no despreciables y una presencia e influencia importante, bien aprovechada para luchar por el ideario católico, en la Organización Internacional, su Asamblea, sus agencias, sus conferencias y la posibilidad, apenas ejercitada, de firmar y ratificar tratados internacionales.

El 4 de octubre de 1965, ya en los epígonos del Concilio Vaticano II (19621965), Pablo VI visitó la ONU y pronunció un discurso en el que declaró que los miembros de la ONU eran «los intérpretes de lo que la sabiduría humana tiene de más elevado, diríamos casi su carácter sagrado", pues lo que los representantes de los Estados proclamaban en ella eran «los derechos y los deberes fundamentales del hombre, su dignidad y libertad y, ante todo, la libertad religiosa ${ }^{7}$, lo que entrañaba un reconocimiento del discurso internacional de los Derechos Humanos.

En este contexto, no ha de extrañar que las oportunidades brindadas en 1968 por el Año Internacional de los Derechos Humanos para convertir estos en servidores de causas precisadas de legitimación, fueran exploradas también con interés por el sector reformista de los democristianos españoles liderados por Joaquín Ruiz Giménez. El ideario de este sector de opinión tolerado, con alguna incomodidad, por los franquistas, se expresaba en aquel momento en Cuadernos para el Diálogo, singular revista española nacida en octubre de 1963 para ser utilizada como "locomotora del cambio" y para promover así ad futurum, a sus colaboradores, como alternativa de recambio al franquismo.

En diciembre de 1968 el equipo editorial de Cuadernos publicó un número extraordinario, en el cual, bajo pretexto de reflexionar sobre la DUDH, sus consecuencias y resultados, lanzaba una crítica al Régimen franquista por su incumplimiento de los Derechos Humanos, en un momento en que el Sistema no podría repudiarlos o negarlos públicamente después de su readmisión, en 1955 en

6. CRAWFord, James: The creation of States in International Law, 1979, p.154.

7. Pablo VI: Visita del Sumo Pontífice Pablo VI a la Organización de las Naciones Unidas. Discurso a los representantes de los Estados. 4 de octubre de 1965. ORe. Buenos Aires. Año XV, n 679, p. 1, 2. <https://w2.vatican.va/content/paul-vi/es/speeches/1965/documents/hf_p-vi_spe_19651004_unitednations.html> [Última revisión 1-03-2018]. 
MARÍA DE LA PAZ PANDO BALLESTEROS

LOS DERECHOS HUMANOS COMO MARCO CULTURAL LEGITIMADOR O MOVILIZADOR

EN EL MESOFRANQUISMO: EL VIGÉSIMO ANIVERSARIO DE LA DUDH EN CUADERNOS...

la ONU, o en 1956 en la OIT, de solicitar su ingreso en la CEE desde 1966 y de la favorable posición del papa Montini a tales principios.

Parece oportuno recordar que Cuadernos para el Diálogo fue no solo una Revista informativa, papel en el que realizó una importante labor en unos años caracterizados por la falta de información o la desinformación, sino una Revista de formación y propaganda política, que fue evolucionando desde posturas moderadamente críticas con el Régimen hasta plantear una abierta oposición al mismo. Del mismo modo, fue una publicación plural, abierta a colaboraciones del más variado signo, la inmensa mayoría de ellas confluyentes en una propuesta democrática; aspecto que no impidió que, en sus inicios, la Revista catalogada inicialmente con razón, y como vimos, como uno de los exponentes más genuinos del pensamiento democristiano, fue atenuando esta orientación a medida que iba cobrando mayor peso el componente socialista. Las fuentes consultadas y nuestras propias investigaciones revelan que 1969 fue un punto de inflexión muy claro en dicha evolución, a la que coadyuvó la evolución ideológica de parte de los asiduos colaboradores de la Revista, el impacto que causó a Ruiz Giménez, en 1968, la incoación de expedientes y sanciones a profesores amigos suyos y colaboradores de la Revista y la muerte por defenestración, ese mismo año, del estudiante Enrique Ruano, en el curso de su detención policial. En definitiva, con el endurecimiento del franquismo la Revista se radicalizó, matizando su religiosidad inicial y adoptando un tono más abiertamente socialista ${ }^{8}$. Llamamos la atención sobre este aspecto porque el número que investigamos, aparece publicado en diciembre de 1968, en pleno proceso del cambio de orientación anteriormente descrito, y puede verse en él no solo una denuncia de la Dictadura sino una abierta apuesta por la Democracia. No en vano el Extraordinario aparece con el título Democracia y Derechos Humanos en clara referencia a que la primera representaba el marco idóneo para el pleno ejercicio y respeto de tales principios.

Los "cuadernistas" que desde la creación de aquel medio de comunicación habían apelado al discurso de los Derechos Humanos, comprendían que la defensa de valores internacionalmente proclamados concedería a su crítica al Sistema una mayor credibilidad y autoridad. Esta línea argumental encontró en la Declaración del Año Internacional de los Derechos Humanos una coyuntura de oportunidad para fundamentar dicha crítica y reivindicar un cambio político para España que posibilitara la defensa de derechos y libertades. En este sentido, en el mes de febrero publicaron un Informe 9 en el que realizaban un estudio comparado entre la Declaración Universal de Derechos y la legislación española, ciñéndose a los derechos civiles y políticos. En él señalaron, a modo de denuncia, aquellos aspectos de la legislación española que no encajaban con la Declaración Universal

8. Pando Ballesteros, M. ${ }^{a}$ Paz: Los democristianos y el proyecto político de Cuadernos para el Diálogo. 1963-1969. Salamanca: Ediciones Universidad de Salamanca, 2005.

9. Informe: "Veinte años de Derechos Humanos", Cuadernos para el Diálogo, 53, febrero 1968, pp. $9-12$ 
LOS DERECHOS HUMANOS COMO MARCO CULTURAL LEGITIMADOR O MOVILIZADOR EN EL MESOFRANQUISMO: EL VIGÉSIMO ANIVERSARIO DE LA DUDH EN CUADERNOS...

y glosaban los artículos más relevantes de la misma, para que el lector pudiera realizar una lectura comparada y sacar sus propias conclusiones. En general, observaban un desfase entre el ideal proclamado y la realidad. En el mes de mayo la Revista sacaba un nuevo Informe en el que se pedía el impulso definitivo para que se efectivaran los derechos políticos de los españoles ${ }^{10}$. Unos meses después, aprovechando el final del año de la Conmemoración de la Declaración Universal, la Revista publicaba un Número Extraordinario dedicado por completo a la temática $^{11}$, dándonos idea de la importancia concedida al tema.

Desde el inicio de dicho número, ya en la presentación ${ }^{12}$, el equipo editorial de la Revista denunciaba el generalizado uso, así como la apelación gratuita y desnaturalizadora a los términos "Derechos Humanos» y "democracia» por regímenes contrarios a tales principios, así como el vaciamiento de contenido al que estaban siendo sometidos los primeros, mientras se imposibilitaba su disfrute real. Afirmaban los "cuadernistas» que Derechos Humanos y democracia eran dos conquistas sin las cuales el futuro de la humanidad estaría comprometido, y que, además, tales recursos ofrecían un eficaz antídoto para el totalitarismo, sistema, que, según ellos, se encontraba en un momento culminante, pese a la derrota de la Alemania y la Italia fascistas en la Segunda Guerra Mundial. Al mismo tiempo, advertían que su apelación a los Derechos Humanos tenía un objetivo militante, de lucha por un futuro en el que estos, y la democracia, dejaran de ser una utopía, o una referencia falsa, para convertirse en una realidad ${ }^{13}$.

1. El análisis de la Declaración Universal de los Derechos Humanos de Cuadernos PARA EL DIÁlOGO: FORMaCión E INFORMaCión CIUDADANa

Un primer objetivo del monográfico de Cuadernos para el Diálogo que ahora analizamos era informar sobre el contenido de la Declaración de 1948. A este fin respondían los artículos de López Aranguren, Francisco Murillo, González Casanova, González Campos y Antonio Truyol, que no realizaban un mero recorrido descriptivo por la DUDH, sino que, de forma crítica, iban señalando, además de

10. Informe: "Las Naciones Unidas, el año internacional de los derechos humanos y España", Cuadernos para el Diálogo, 56, mayo 1968, pp. 20-22.

11. Democracia y Derechos Humanos, extraordinario XII, diciembre 1968.

12. "Presentación", Cuadernos para el Diálogo, extraordinario XII, diciembre 1968, p. 3.

13. La utilización por los democristianos de Cuadernos en la España franquista de los derechos humanos como "marco cultural movilizador" contra la dictadura es una prueba más del error de S. TARROW, conocido especialista en movimientos sociales, cuando afirmó (en El poder en movimiento. Madrid: Alianza Editorial, 1997, pp. 225 y ss.) que no cabía esperar tal utilización fuera del marco anglosajón, como en su día apuntó la Profesora M. ${ }^{a}$ Esther MarTínez QuinTEIRo en «Movilización social y derechos humanos». Análisis histórico del Derecho al Trabajo. En Derechos Humanos, $n .{ }^{\circ}$ monográfico del Boletín del Ilustre Colegio de abogados de Madrid, 9, julio 1998, p. 271, nota 4, y como reconocería más tarde el propio Tarrow. 
MARÍA DE LA PAZ PANDO BALLESTEROS

LOS DERECHOS HUMANOS COMO MARCO CULTURAL LEGITIMADOR O MOVILIZADOR

EN EL MESOFRANQUISMO: EL VIGÉSIMO ANIVERSARIO DE LA DUDH EN CUADERNOS...

su potencial emancipador, las lagunas y deficiencias del texto y apuntando alternativas de mejora.

El, en su día, catedrático de Ética y Sociología de la Universidad de La Universidad de Madrid, expulsado de la misma por su disidencia en 1965, José Luis López Aranguren ${ }^{14}$, muy conocido en la España de entonces por su tránsito desde posiciones falangistas al rechazo de la Dictadura, reflexionaba en Cuadernos, sobre el sentido de la Declaración Universal de los Derechos Humanos de 1948. Tras una valoración general sobre las clásicas Declaraciones liberales de Derechos, afirmaba que no había solución de continuidad entre las viejas y las nuevas Declaraciones. A pesar de ser esto bastante discutible, consideraba la elaborada por la ONU, como una proclamación "ecléctica» y ya no meramente individualista. Subrayaba que aunque no faltaran en ella muchos artículos destinados a salvaguardar los derechos del individuo, éstos compartían espacio con un plural elenco de "derechos sociales», sin percibir que incluso los más emblemáticos de estos ya habían aparecido en la Revolución Francesa y que, como en ella, habían sido concebidos por los autores de la Declaración como derechos individuales, toda vez que se imputaban, como los demás, a «la persona», y no a la colectividad. Así lo destacó, entre otros autores, Ara Pinilla ${ }^{15}$, o la misma "Declaración y Programa de Acción de Viena", elaborados por la muy importante Conferencia Mundial de Derechos Humanos de Viena, de 25 de junio de 1993, en el párrafo 2 de su preámbulo.

Sería precisamente en los "derechos sociales", supuestamente inmunes al individualismo, en los que el autor que nos ocupa se detendría complacido: López Aranguren calificaba como "especialmente novedosos» (para una fecha como 1948) aquellos artículos que "dotaban a esos derechos sociales de contenido económico, como el derecho al trabajo y el de la protección contra el desempleo, el de seguridad social, el derecho a disfrutar de un determinado nivel de vida, de tiempo libre, así como los relativos al plano cultural, como la democratización de la educación y la participación en la cultura", señalando también con satisfacción que a la libertad de asociación se le dio una orientación social para hacerla desembocar en la "libertad de sindicación» (cuya prohibición, denunciada una y otra vez en la OIT, se erigió en caballo de batalla contra el Régimen).

No por celebrar tales avances ahorraba Aranguren críticas a la Declaración Universal. Censuraba en primer lugar su conocida falta de carácter jurídicamente vinculante, algo lamentado explícitamente por la mayor parte de los coautores del monográfico estudiado. En segundo lugar, lamentaba el diferente tratamiento dado, en los textos normativos de la ONU, a los derechos usualmente denominados de "primera generación" (civiles y políticos) y los convencionalmente conocidos como "derechos de segunda generación» (económicos, sociales y culturales), al

14. López Aranguren, José Luis: "Sentido de una Declaración Universal de los Derechos Humanos", Cuadernos para el Diálogo, extraordinario XII, diciembre 1968, pp. 7-8.

15. Ara Pinilla, Ignacio: Las transformaciones de los derechos bumanos. Madrid: Tecnos, 1990, pp. $104-105$. 
LOS DERECHOS HUMANOS COMO MARCO CULTURAL LEGITIMADOR O MOVILIZADOR EN EL MESOFRANQUISMO: EL VIGÉSIMO ANIVERSARIO DE LA DUDH EN CUADERNOS...

hacerse depender los segundos en los textos oficiales de las Naciones Unidas de los recursos de los que los Estados dispusieran, aunque también de la cooperación internacional, y al conformarse lo normado con una implementación "progresiva", y por tanto no necesariamente inmediata (como se requería para los derechos civiles y políticos) de los «derechos sociales», crítica que se prolonga hasta nuestros días. Paradójicamente, Aranguren consideraba gratuita la pretensión de dar efectividad a todos los derechos humanos al mismo tiempo.

Se negaba también a aceptar que los derechos económicos, sociales y culturales tuvieran un carácter que calificaba de "secundario", el catedrático de Derecho Político, discípulo del conservador democristiano Sánchez Agesta, el sociólogo y politólogo Francisco Murillo Ferrol, catedrático de la universidad Complutense de Madrid $^{16}$. Si bien aceptaba que la implementación de tales derechos podría estar condicionada por una determinada situación social y económica, tal concesión al principio de realidad no debería afectar, a su modo de ver, a la teórica importancia que le concedía. Reconocía el autor la falta de capacidad del Estado intervencionista para cumplir las promesas en materia de derechos económicos y sociales, dada la necesidad de allegar cuantioso recursos financieros y la compleja organización burocrática que requerían y afirmaba que solo con una "auténtica democracia económica" cabría llegar a la efectiva vigencia de tales derechos, aunque advertía que la implementación de tal "democracia» exigiría una profunda transformación de todo el sistema, para que permitiera una plena y activa participación ciudadana en la toma de las decisiones, para que los derechos de prestación no aparecieran como la obtención de unos beneficios graciosamente concedidos por el poder.

Finalmente el Catedrático de Sociología mostraba una opinión conservadora al afirmar que no procedía mitificar los derechos sociales y que su carácter imprescindible señalaría la afluencia de un sistema, de tal modo contrario a la protección social, que iría contra la dignidad humana.

Como derecho social cataloga el derecho a la información el constitucionalista González Casanova, uno de los fundadores del Front Obrer de Catalunya, al que perteneció hasta 1970 cuando se incorporó, primero al Partit Socialista de Catalunya-Congrés, y después al Partit dels Socialistes de Catalunya, justificando tal ubicación por el derecho que tienen los ciudadanos a que se les ofrezca una información veraz y objetiva. Para atenderlo el Estado no podía ser un elemento pasivo sino que tenía que ejercer una acción de fomento y tutela. Sostenía que tampoco la libertad de expresión podía ser considerada ya como un derecho meramente negativo, ni como un mero instrumento de acción política, sino que era de facto un instrumento imprescindible para asegurar el desarrollo cultural y económico, estando el Estado obligado a asegurar o respaldar su protección ${ }^{17}$.

16. Murillo, Francisco: «Los derechos económicos y sociales», Cuadernos para el Diálogo, extraordinario XII, diciembre 1968, pp. 15-16.

17. González Casanova, José Antonio: "El derecho a la libre expresión y a la información», Cuadernos para el Diálogo, extraordinario XII, diciembre 1968, pp. 17-19. 
MARÍA DE LA PAZ PANDO BALLESTEROS

LOS DERECHOS HUMANOS COMO MARCO CULTURAL LEGITIMADOR O MOVILIZADOR

EN EL MESOFRANQUISMO: EL VIGÉSIMO ANIVERSARIO DE LA DUDH EN CUADERNOS...

Las libertades de expresión e información eran viejas reivindicaciones de los democristianos de Cuadernos que desde los primeros números de la Revista mostraron una gran preocupación por ellas. No era de extrañar, su instrumento de acción por excelencia era precisamente la palabra escrita en un contexto de censura. Sin libertad de expresión ni siquiera cabía una eficaz defensa o propaganda de los demás Derechos Humanos. La primera y los segundos en su conjunto, constituían reivindicaciones interdependientes, y ambas eran estratégicamente imprescindibles para legitimar críticas y exigir reformas. Con el paso del tiempo, la prensa hubo de compartir protagonismo con otros medios de comunicación para llegar a las masas y los "cuadernistas» reivindicaban también para ellos tales libertades. En 1968, desde posiciones socialistas, González Casanova proponía la conversión de radio-televisión en un servicio público monopolizado. Los argumentos radicaban en que el Estado debía poner los medios para impedir el potencial o efectivo sectarismo y el engaño de los Gobiernos y que la información cayera en manos de grupos de poder cuya aspiración fuera subrogarse en el disfrute del poder del Estado, sin pretensión de transformación social, ni de desarrollo económico, como afirmaba la llamada "doctrina del desarrollo", respecto a la libertad de expresión y de información.

En definitiva, para González Casanova, el uso «democrático» de los medios de información con fines de liberación popular, que reivindicaba, dependería de su institucionalización y defensa jurídicas a partir de un régimen político en el que el Estado surgiera del pueblo y no fuera instrumento de los grupos políticos, sociales o económicos particulares.

\section{INSTRUMENTOS LEGITIMADORES DE LA OPOSICIÓN Y DE LA PROTECCIÓN Y REIVINDICACIÓN De Derechos y Libertades}

La apelación a los Derechos Humanos, basada en el consenso internacional, constituía un importante instrumento para la deslegitimación de la Dictadura y la legitimación de sus oponentes. Para aquellos países cuyos regímenes políticos no garantizaran la protección de los derechos de las personas ni su libre ejercicio, caso de España, el discurso internacional podía servir de referente para exigir su ejercicio y llegado el caso para denunciar su transgresión (recurso que los articulistas pretendían utilizar para presionar al Régimen para que garantizara las imprescindibles libertades). Lo ideal en palabras del democristiano Aguilar Navarro ${ }^{18}$, sería que el proceso de positivación de los derechos en el marco del estado y en el internacional estuvieran interrelacionados.

18. Aguilar Navarro, Mariano: "Significación del año de los derechos humanos", Cuadernos para el Diálogo, extraordinario XII, diciembre 1968, pp. 4-6. 


\section{MARÍA DE LA PAZ PANDO BALLESTEROS \\ LOS DERECHOS HUMANOS COMO MARCO CULTURAL LEGITIMADOR O MOVILIZADOR \\ EN EL MESOFRANQUISMO: EL VIGÉSIMO ANIVERSARIO DE LA DUDH EN CUADERNOS...}

Sería el articulista internacionalista de orientación comunista González Campos $^{19}$, entonces Profesor de Derecho Internacional de la Universidad Complutense de Madrid, catedrático desde 1971, quien reflexionara, en el monográfico, sobre las posibilidades que el orden internacional ofrecía a los particulares en materia de protección, respeto y promoción de sus derechos y libertades ${ }^{20}$.

Como es sabido, la legislación internacional sobre Derechos Humanos se concretaba a menudo en Resoluciones, Declaraciones, y Recomendaciones. Sin embargo, se lamentaban diversos autores ${ }^{21}$ de que principios tan importantes como los Derechos Humanos no fueran, en ocasiones, desarrollado más que a través de una recomendación y carecieran de fuerza jurídica vinculante (lo que facilitaba el descompromiso de la Dictadura para con ellos), compromiso que solo se alcanzaría cuando los Estados ratificaran el Pacto Internacional sobre Derechos Económicos, Sociales y Culturales y el relativo a los Derechos Civiles y Políticos, así como el Protocolo Opcional de este último. Esta legislación constituía el «Estatuto internacional del hombre», en palabras de González Campos, ó bien la "Constitución Internacional», como la definía el democristiano Aguilar Navarro ${ }^{22}$.

Junto al discurso internacional de la ONU, aparecieron, para promover los Derechos Humanos, los Sistemas Regionales. En este sentido, los derechos del hombre fueron un elemento fundamental también en el proceso de integración europea $^{23}$, del que España estaba apartada, por el momento.

19. Roberto Mesa realizó una elogiosa descripción de este discípulo de Mariano Aguilar Navarro Roberto Mesa en la que señalaba: «Julio González Campos también era (...) un profesor ejemplar, (...) jurista excepcional, rápido en el juicio y certero siempre en el análisis (...), era el rigor, el marxismo y la ubicación en el sitio justo y en el momento oportuno». Fernández Rozas, José Carlos: «El profesor Julio D. González Campos y el arte de la paz». En: Pacis artes. Obra homenaje al profesor Julio D. González Campos. Madrid: Eurolex, 2005, pp. 51-142.

20. GonzÁlez CAmpos, Julio: "El orden internacional y la realización de los derechos humanos", Cuadernos para el Diálogo, extraordinario XII, diciembre 1968, pp. 31-34.

21. Truyol, Antonio: "Vigencia internacional de los derechos humanos", Cuadernos para el Diálogo, extraordinario XII, diciembre 1968, pp. 35-37; GonZÁlez CAmpos, Julio: op. cit.; RuIZ-Giménez, Joaquín: "protección de derechos humanos y reforma de estructuras", Cuadernos para el Diálogo, extraordinario XII, diciembre 1968, pp. p. 9-14.

22. El catedrático democristiano de Derecho Internacional Mariano Aguilar Navarro explica de forma muy detallada la evolución del reconocimiento de los Derechos Humanos hasta culminar en ese proceso de internacionalización. Desde una primera etapa en la que predominaría el Derecho Natural, hasta la fase de positivación tanto a nivel estatal, que arrancaría con el constitucionalismo del s. XIX, como posteriormente, a nivel internacional. En ese proceso, la Sociedad de Naciones representaría una situación intermedia, de transición entre ambos niveles. El autor valora positivamente el esfuerzo del pacto Ginebrino para garantizar la seguridad, el mantenimiento y de defensa de la paz y un orden de cooperación. Por su parte, la creación de la ONU habría representado el inicio hacia la consolidación del proceso de internacionalización, concretándose paulatinamente, desde la Declaración de 1948 a los pactos de 1966, que representan la evolución desde la fase de la formulación programática hasta la de la positivación plena, en la que estos derechos fundamentales constituyen el principio de legitimidad internacional.

23. Aguilar Navarro, Mariano: op. cit. 
MARÍA DE LA PAZ PANDO BALLESTEROS

LOS DERECHOS HUMANOS COMO MARCO CULTURAL LEGITIMADOR O MOVILIZADOR

EN EL MESOFRANQUISMO: EL VIGÉSIMO ANIVERSARIO DE LA DUDH EN CUADERNOS...

Si bien el Derecho Público internacional de los Derechos Humanos representaba un sistema de protección de los ciudadanos, tanto ante prácticas antidiscriminatorias, como contra medidas arbitrarias del poder político, tal como se hacía saber a los lectores de Cuadernos, su ejecución resultaba compleja, lamentándose de ello autores como González Campos que no renunciaba a describir los mecanismos de control previstos por el Comité de Derechos Humanos y la posibilidad de reclamación y denuncia de los particulares pese a la escasa eficacia de tales recursos ${ }^{24}$.

Ante la falta de competencias de la ONU para imponerse a los Estados, RuizGiménez ${ }^{25}$ proponía una reforma de la Declaración de 1948 para hacerla más operativa, procurando que se crearan órganos que tuvieran jurisdicción y competencia sobre todas las cuestiones relacionadas con derechos y libertades del hombre, pero puesto que tales voluntarismos no estaban llamados a tener éxito inmediato, y mientras la soñada reforma se produjera, los "cuadernistas» insistirían en que, como mínimo, no debería desestimarse la DUDH como paradigma, aún dentro de sus limitaciones. En este sentido Antonio Truyol ${ }^{26}$ advertía que pese al carácter no vinculante de la Declaración, nadie podía discutir su obligatoriedad moral para los miembros de la organización pues el Art. 56 de la Carta de la ONU de 1945 requería tomar medidas en aras del respeto a los derechos humanos y de las libertades fundamentales. Del mismo modo, el autor advertía que los países no podían alegar que quedaban fuera de la intervención de la ONU los asuntos que eran de la jurisdicción interna de los Estados, porque la Carta rompía con el principio de que un Estado podía tratar a sus súbditos arbitrariamente, al haberlo sustituido por la idea de que el respeto y la protección a los derechos y a las libertades fundamentales constituían una cuestión internacional.

La falta de un carácter jurídicamente vinculante de los textos internacionales llevó a los articulistas que participaban en este número de Cuadernos $^{27}$ a dirigir su mirada hacia el Convenio para la Protección de los Derechos Humanos y las Libertades Fundamentales, firmada en Roma en 1950, por los estados miembros del Consejo de Europa, y completada por Protocolos adicionales en el campo de los derechos de primera generación, adoptados en 1952, y por la Carta Social

24. Se informaba a los lectores de Cuadernos cómo los mecanismos de control previstos por el Comité de Derechos Humanos pasaban porque cada Estado miembro informara a los órganos supranacionales sobre las medidas pendientes y aquellas que iba adoptando para promover los derechos y libertades, también era posible un control de Estado a Estado, pero al individuo solo se le permitía su intervención si el Estado nacional aceptaba ratificar los instrumentos que garantizaran que los particulares pudieran presentar reclamaciones contra la violación de un Convenio que el propio Estado pudiera cometer (no era el caso de España), y, aún así, se lamentaba el articulista de que tanto la intervención de organismos no gubernamentales, como la de las particulares carecieran de eficacia real. Julio González Campos «El orden internacional y la realización de los derechos humanos». GonzÁLEz CAmpos, Julio: op. cit.

25. Ruiz-Giménez, Joaquín: op. cit.

26. Truyol, Antonio: op. cit.

27. Ruiz-Giménez, Antonio Truyol, Julio González Campos 


\section{$102 \quad$ MARÍA DE LA PAZ PANDO BALLESTEROS \\ LOS DERECHOS HUMANOS COMO MARCO CULTURAL LEGITIMADOR O MOVILIZADOR EN EL MESOFRANQUISMO: EL VIGÉSIMO ANIVERSARIO DE LA DUDH EN CUADERNOS...}

Europea firmada en Turín en $1961^{28}$. Los citados textos constituían un sistema legal y representaban el mayor avance realizado para tutelar los derechos humanos en el plano internacional, pero desgraciadamente España también quedaba fuera de este ámbito de protección.

Para otros autores era la doctrina de una Iglesia «evolucionada» (y, se sugería, entre líneas, más abierta que el Régimen político español del momento), reconciliada, ya a la altura de 1968, con la defensa y promoción de los Derechos Humanos ${ }^{29}$, la que ofrecería un refugio alternativo frente al «desamparo internacional» en que dejaba al ciudadano de a pie el carácter no vinculante de la Carta Internacional en ciernes. En efecto, en 1968, desde Cuadernos, se encargaba de tal funcional planteamiento, echando mano de un discurso ad hoc, González Campos, que (además de proponer un sistema de cooperación voluntaria entre los Estados para adoptar aquellas medidas tendentes al respeto y desarrollo de los derechos humanos, al recordar el reciente papel de la Iglesia en la promoción de tales derechos, sobre todo tras el Concilio Vaticano II, mataba dos pájaros de un tiro: justificar a los promotores de Cuadernos por avanzar hacia fórmulas más democráticas y subrayar la incoherencia de aquellos franquistas que autoproclamándose nacionalcatólicos, transgredían valores oficialmente respaldados por su Iglesia u hostigaban en mayor o menor grado a quienes se mostraban (como el grupo "cuadernista") más permeable a sus enseñanzas. En efecto, siguiendo a González Campos ${ }^{30}$, dado que se consideraba que la doctrina social de la Iglesia Católica constituía un valor «superior» en el ordenamiento jurídico franquista, como un criterio conforme al cual podía juzgarse sobre la validez de las reglas y de las decisiones del sistema, se sobreentendía que los particulares podrían usar el "derecho de petición», así como el llamado "recurso de contrafuero" no solo para denunciar una disposición como contraria a las Leyes y Principios Fundamentales del Movimiento, sino para impugnarla como contraria a los preceptos de la doctrina de la Iglesia en materia de derechos y libertades.

No solo el consenso internacional, o el discurso católico internacional del Vaticano II constituían importantes instrumentos legitimadores para la reivindicación de los Derechos Humanos, el propio Régimen ofrecía «resquicios» para argüir en su defensa, pues los había adoptado formalmente como normas fundamentales de su ordenamiento jurídico en el Fuero de los Españoles de $1945^{31}$. No obstante sus

28. El Consejo de Europa incluía, en ese momento, a 18 miembros, que representaban a los Estados de Europa occidental salvo Finlandia, España y Portugal. Constaba de dos órganos la Comisión Europea de Derechos Humanos, a la que tenían acceso junto a los particulares, organizaciones no gubernamentales y los grupos de particulares de los estados que aceptaran los mecanismos del control establecidos por el convenio de Roma y el Tribunal Europeo de Derechos Humanos donde podían llegar las demandas de los particulares.

29. Dicho proceso será analizado en las páginas siguientes de este mismo artículo.

30. González Campos, Julio: op. cit.

31. Para valorar críticamente las aportaciones del pensamiento jurídico español a la filosofía de los derechos humanos entre 1939 y 1975 puede consultarse a García Manrique. En 1975 el profesor 


\section{MARÍA DE LA PAZ PANDO BALLESTEROS \\ LOS DERECHOS HUMANOS COMO MARCO CULTURAL LEGITIMADOR O MOVILIZADOR 103 EN EL MESOFRANQUISMO: EL VIGÉSIMO ANIVERSARIO DE LA DUDH EN CUADERNOS...}

falacias, incluso esta Ley fundamenta franquista ofrecía a los católicos reformistas una plataforma argumental para exigir que se dotara de real significado a aquello mismo que se predicaba, o que se avanzara en los desarrollos legales puntuales de los valores reconocidos, hacia fórmulas homologables internacionalmente.

Sin embargo, como desde Cuadernos para el Diálogo se encargaría de subrayar el entonces democristiano, más tarde socialista, Torres Boursault ${ }^{32}$, un mero repaso de enunciados del Fuero no dejaría de arrojar un resultado engañoso. Estudiando sus contenidos en profundidad podría verse que las leyes fundamentales no pasaban de ser una pura enumeración programática de derechos, con un planteamiento admonitivo sin carácter normativo. Leyes de rango inferior debían encargarse de dotarlos del mismo, acomodándolos a los principios generales del Movimiento. Por otro lado, denunciaba el abusivo margen de discrecionalidad interpretativa que los textos jurídicos sobre derechos individuales dejaban a los órganos administrativos y jurisdiccionales ${ }^{33}$. Aspectos que llevaron al autor a señalar que el problema, a la altura de 1968, no era tanto el del reconocimiento literal de los derechos, sino que su interpretación y aplicación dependían estrictamente de la voluntad política, convirtiendo en inconsistente la sedicente "democracia orgánica».

La denuncia por Cuadernos del abusivo tratamiento que de la doctrina de los Derechos Humanos realizaba la Dictadura franquista, no se reducía a constatar el vacío de contenido al que quedaba sometido el articulado del Fuero franquista o a la estéril inflación verbalista, en palabras del democristiano Ortega Díaz Ambrona ${ }^{34}$, que provocaba el recurrente uso del término «Derechos Humanos» por los políticos franquistas.

SÁNCHEZ DE LA TORRE publicó una monografía sobre el Fuero (Comentario al Fuero de los Españoles. Madrid: Instituto de Estudios Políticos, 1975) en la que, distanciándose de la visión crítica del franquismo, contenida en el libro Teoría y experiencia de los derechos humanos. Madrid: Gregorio de Toro, 1960, (dentro de las coordenadas del pensamiento católico renovador), propende a un descriptismo más contemporizador con el sistema que periclitaba. Véanse los comentarios a la obra de Sánchez de la Torre en García ManRiQue, Ricardo: La filosofía de los derechos humanos durante el franquismo. Madrid: CEC, 1996, pp. 402, 418. Sus referencias al Fuero en ibidem, pp. 22, 46, 147-48, 163, 114, 155.

32. Torres Boursault, Enrique: "Cara y cruz de los derechos humanos", Cuadernos para el Diálogo, extraordinario XII, diciembre 1968, pp. 20-23.

33. En la práctica, según Torres Boursault, el Fuero había dado lugar a disposiciones restrictivas en relación a la Declaración de la ONU. Tal vicio podía detectarse en lo concerniente a Jurisdicciones penales especiales, a lo regulado sobre el derecho de asociación, orden público, secuestros oficiales, libertad religiosa, representación familiar y diversos contenidos del Código Penal, la Ley de Cortes o la Ley de Unidad Sindical. (Todos ellos caballos de batalla del momento tanto entre los ortodoxos del franquismo y quienes tímidamente iniciaban una actitud evolucionista desde dentro del Sistema, como entre franquistas y opositores más decididos). El autor censuraba especialmente la internacionalmente denostada Ley de Orden Público, que constreñía la posibilidad de reunión y manifestación y facilitaba la represión de las libertades de expresión, prensa e imprenta, ibidem.

34. Díaz Ambrona, Ortega: "Derechos fundamentales y realidad jurídica», Cuadernos para el Diálogo, extraordinario XII, diciembre 1968, pp. 11-12. 
104 MARÍA DE LA PAZ PANDO BALLESTEROS

LOS DERECHOS HUMANOS COMO MARCO CULTURAL LEGITIMADOR O MOVILIZADOR

EN EL MESOFRANQUISMO: EL VIGÉSIMO ANIVERSARIO DE LA DUDH EN CUADERNOS...

López Aranguren ${ }^{35}$ acusaba al Régimen, sin mencionarlo directamente, de intentar detener el tiempo cuando de forma simultánea promulgaba solemnes Declaraciones y declaraba como inmutables los principios del Movimiento. Más preciso se mostraba Julio González Campos al denunciar que España, hasta hacía muy poco tiempo, no hubiera ratificado ninguno de los convenios internacionales aprobados en 1965, imposibilitando así que los españoles pudieran presentar, cuando entraran en vigor, denuncias al Comité de Derechos Humanos. Por otro lado, el autor también criticaba que no existieran en nuestro país "Comités nacionales de asesoramiento sobre Derechos Humanos", como ocurría en otros lugares, proponiendo como alternativa la organización de un fuerte movimiento asociativo que se encargara de llevar a cabo las funciones de estudio, información y difusión de los objetivos de la Declaración. A falta del mismo, la Revista suplía tal carencia perfectamente, no solo mediante la publicación del monográfico ahora analizado, sino a través de los artículos que aparecían en cada número mensual de Cuadernos, compromiso visible desde la creación de la Revista.

Más prudente con la denuncia de la situación en España se mostraba un joven Jorge Esteban ${ }^{36}$, hoy prestigioso Catedrático de Derecho Constitucional que, en el artículo titulado "Historia de los Derechos Humanos en España», realizó un recorrido histórico por la evolución de tales principios en nuestro país a través de su desarrollo constitucional hasta la Constitución de 1931, último texto que analizó, de modo que no entró a valorar el tratamiento y la instrumentalización que la Dictadura hizo de tales principios.

Jorge Esteban planteaba que hasta 1936 los Derechos Humanos habían ido perfilándose y concretándose progresivamente, pese a ciertos retrocesos, considerando que fueron las dos constituciones republicanas las que alcanzaron mayor desarrollo en el enunciado de tales derechos, aunque denunciaba la falta de correspondencia entre el reconocimiento de derechos que incluían y su aplicación. Sin reducirse al estudio teórico, el autor acompañaba su análisis de una reflexión social de las insuficiencias del desarrollo de la igualdad, la propiedad, la libertad, o la seguridad, justificándolas por el fracaso de una auténtica revolución burguesa en nuestro país. Sin una clase media a escala nacional, existiendo unas desigualdades extremas y con una clase dirigente que únicamente representaba intereses particulares, argumentaba Jorge Esteban, era imposible hablar de Derechos Humanos en su concepción liberal-burguesa.

También el socialista Elías Díaz ${ }^{37}$ optó por presentar un análisis histórico del discurso de los Derechos Humanos contenido en la Declaración de los Derechos del Hombre y del Ciudadano de 1789, pionera en muchos aspectos. Destacaba del

35. López Aranguren, José Luis: op. cit., pp. 7-8.

36. Esteban, Jorge: "Historia de los Derechos Humanos en España», Cuadernos para el Diálogo, extraordinario XII, diciembre 1968, pp. 25-29.

37. Díaz, Elías: «La declaración de Derechos del Hombre y del Ciudadano en la Revolución Francesa", Cuadernos para el Diálogo, extraordinario XII, diciembre 1968, pp. 39-42. 
MARÍA DE LA PAZ PANDO BALLESTEROS

LOS DERECHOS HUMANOS COMO MARCO CULTURAL LEGITIMADOR O MOVILIZADOR

EN EL MESOFRANQUISMO: EL VIGÉSIMO ANIVERSARIO DE LA DUDH EN CUADERNOS...

texto que no se limitara a enunciar los derechos que consideraba "naturales, inalienables y sagrados ${ }^{38}$, sino que estableciera la organización estatal más coherente para la defensa y protección de dichos derechos, al incluir en el articulado el principio de la soberanía nacional y de la separación de poderes: sustancial aviso para navegantes en un contexto como el español del momento. El Filósofo del Derecho salamantino concluía afirmando que la connotación última de la Declaración al igual que el resultado de la Revolución, era su carácter netamente liberal, en el que los factores conservadores burgueses se imponían sobre las implicaciones revolucionarias que podrían haber derivado de una concepción integral, no simplemente formal y jurídica de la igualdad, que sería después la determinante en el socialismo. Aunque el autor no renunciaría a denunciar que el primer liberalismo no reconocía los derechos a todos los hombres, sino solo a los propietarios, olvidaba señalar que se los negaba también a la totalidad de las mujeres.

No sobraba, a nuestro modo de ver, una referencia, en el monográfico de la Revista, a dicha Declaración de Derechos francesa, dado que sus colaboradores habían repasado los textos decimonónicos españoles para los que el documento galo había servido de inspiración. Es destacable el protagonismo que el número concede a las revoluciones liberales y a las constituciones y Declaraciones de Derechos a las que dieron lugar (el monográfico llegó a recordar que 1968 conmemora también el centenario de la revolución española de septiembre de 1868, que merecía ser recordada por el impulso que dio a los derechos y libertades de los españoles ${ }^{39}$ ), lo que no sería algo extraño, dado que las revoluciones liberales contra el absolutismo se convirtieron en el contexto en el que cristalizaron los textos más influyentes de los Derechos del Hombre, si no fuera porque esta ideología estuvo totalmente denostada durante la Dictadura y la historia del s. XIx español desapreció de los programas curriculares.

\section{La Democracia como modelo ideal para el ejercicio de los Derechos Humanos}

Para los cuadernistas existía una directa relación entre Derechos Humanos y Democracia, como el sistema ideal para que aquellos principios pudieran desarrollarse, ser protegidos y ejercidos por la ciudadanía.

Decimos bien cuando hablamos de democracias en plural, pues no solo en el monográfico analizado se abordaban diferentes modelos de tal sistema organizativo, sino que numerosos politólogos, reconociendo la complejidad del término, advierten que "no existe un "modelo de democracia" (...), lo que hay son pueblos

38. El autor se detiene en el análisis de la libertad, la igualdad y la propiedad, reflexionando sobre el significado de cada uno de ellos.

39. González Campos, Julio: op. cit. 
LOS DERECHOS HUMANOS COMO MARCO CULTURAL LEGITIMADOR O MOVILIZADOR EN EL MESOFRANQUISMO: EL VIGÉSIMO ANIVERSARIO DE LA DUDH EN CUADERNOS...

enfrentados a distintos problemas llegando a soluciones que tienen «un aire de familia", esto es "democracias" " 40 .

Un número importante de autores valoraban en Cuadernos las características que deberían tener las democracias para que los Derechos Humanos pudieran garantizarse. El democristiano Aguilar Navarro fundamentaba la necesidad de realizar cambios políticos tendentes a la democracia en la propia Declaración de Derechos de 1948, al explicar que dicho texto suponía una nueva forma de concebir el Estado y el ejercicio del poder político. La Declaración representaba, en palabras del autor, la confirmación de un proceso de democratización y de legalidad de la acción del Estado que debía reflejarse en una racionalización del poder político en la forma de entender la acción del legislativo: parlamentarismo; imponiendo el principio de legalidad administrativa al que habría de ajustarse el ejecutivo, factor indispensable en la configuración del Estado de Derecho y fortaleciendo la política social del Estado.

También el Catedrático liberal de Derecho Político, Carlos Ollero ${ }^{41}$, generalmente presentado como "demócrata» conservador, reflexionaba sobre el modelo de la democracia occidental, destacando, en 1968, como rasgo distintivo de la misma su vinculación con la libertad. Para que la Democracia fuera posible se requería, según el autor, de la elección como fuente legitimadora de poder, de la participación popular activa y del control democrático, y además que fueran ejercidos libremente. Estos aspectos que representan los argumentos clásicos de las democracias liberales han sido muy estudiadas por Samuel P. Huntington, para quien dicho sistema representaba un procedimiento de selección de dirigentes ${ }^{42}$.

En una fecha como 1968 cuando los modelos sociopolíticos socialistas y capitalistas, en los que estaba organizada la estructura sociopolítica mundial en plena Guerra Fría, competían por imponerse, varios autores reflexionaban en el monográfico analizado acerca de la relación entre el marxismo y el socialismo con la democracia e incluso en la influencia que dichas ideologías pudieron tener en el desarrollo de las democracias occidentales capitalistas. En este sentido Ollero abordaba en su artículo la contribución del sistema capitalista a las transformaciones que habían dado lugar al Estado Democrático de bienestar social, así como la influencia del socialismo en dicho proceso. El autor señalaba el periodo de entreguerras como un momento importante en el proceso de democratización política al que había contribuido, junto al aumento de la intervención estatal, la renuncia comunista a la revolución mundial en favor de la revolución en un solo país, influenciada por el socialismo reformista, no comunista.

40. Dunn, John: Democracia: el viaje inacabado (508 a.C.-1993 d.C). Barcelona: Tusquets, 1995 LIPHART, Arend: Democracias contemporáneas. Barcelona: Ariel, 1991.

41. Ollero, Carlos: "Democracia occidental y libertad», Cuadernos para el Diálogo, extraordinario XII, diciembre 1968, pp. 49-51.

42. Huntington, Samuel P.: La tercera ola: la democratización a finales del siglo xx. Barcelona: Paidós, 1994. 
MARÍA DE LA PAZ PANDO BALLESTEROS

LOS DERECHOS HUMANOS COMO MARCO CULTURAL LEGITIMADOR O MOVILIZADOR

EN EL MESOFRANQUISMO: EL VIGÉSIMO ANIVERSARIO DE LA DUDH EN CUADERNOS...

Dicho proceso de democratización se habría profundizado después de 1945, afirmaba Ollero, al producirse un acercamiento entre las libertades formales y las reales, proceso al que habría contribuido no solo el avance tecnológico y el desarrollo económico occidental, sino también el propio marxismo, que ampliaba su influencia en Europa y la adopción por parte de los estados occidentales de principios hasta entonces considerados propios de dichas ideologías. El autor señalaba que los estados capitalistas tuvieron que reconocer que para que un sistema de libertades fuera efectivo se precisaban condiciones materiales que posibilitaran su disfrute por la totalidad del pueblo, viéndose obligados a aceptar la influencia social y política del actor económico, contribuyendo así el socialismo a que el Estado capitalista se convirtiera en empresa de bienestar social y fracasando, de ese modo, al mismo tiempo, el pronóstico marxista sobre la dinámica inevitable de la democracia capitalista.

Apostaba finalmente Ollero porque el desarrollo económico, el progreso tecnológico y la sociedad de consumo occidental fueran acompañadas de cambios en la estructura sociopolítica y produjera una revisión profunda en la producción de bienes y en la gestión y el control de las fuerzas económicas.

Por su parte, López Aranguren ${ }^{43}$ resaltaba las diferencias en cuanto a los derechos que priorizaban los modelos de democracia en liza. El occidental de libertad jurídico-formal y el sistema socialista que priorizaría la elevación generalizada del nivel de vida, según el principio de igualdad, como un proceso para alcanzar la libertad. Consideraba ambos modelos defectuosos e insatisfactorios en cuanto sistemas economicistas y materialistas, aunque viables. Por un lado, el paleocomunismo forzaría a vivir para producir, conduciría a la burocratización de la existencia y a la colectivización de la que se hallaba ausente toda democracia real, mientras que el neocapitalismo empujaría a vivir para consumir y a una manipulación que privaría a la mayoría de capacidad de elección real y por tanto de verdadera libertad, reivindicando finalmente una nueva y humana forma de vida que no se hiciera de espaldas a la moral.

Más avanzado en sus consideraciones se mostraba el socialista Enrique Tierno Galván ${ }^{44}$ que encontraba un mínimo de homogeneidad entre los diversos países socialistas y la democracia, pese a las diferencias que reconocía entre los modelos de la República Popular China, Checoslovaquia o Cuba ${ }^{45}$. No obstante,

43. López Aranguren, José Luis: op. cit.,

44. Tierno Galván, Enrique: «La democracia en los países socialistas», Cuadernos para el Diálogo, extraordinario XII, diciembre 1968, pp. 52-53.

45. El "viejo profesor» distinguía entre aquellos países que podían aprovechar parte de su tradición histórica como soporte ideológico y, en ocasiones, práctico para la Revolución y los que tenían que anular las condiciones históricas heredadas. Punto de partida que produciría variantes entre el socialismo democrático y diferencias en cuanto a la forma para conseguirlo. El caso de Checoslovaquia sería, para el autor, un ejemplo claro de contradicción entre un pasado con un avanzado estado de desarrollo ideológico y económico y la presión política por implantar una democracia socialista, lo que provocó notorias dificultades. Ibidem. 
LOS DERECHOS HUMANOS COMO MARCO CULTURAL LEGITIMADOR O MOVILIZADOR EN EL MESOFRANQUISMO: EL VIGÉSIMO ANIVERSARIO DE LA DUDH EN CUADERNOS...

argumentaba que la democracia socialista era esencialmente distinta a la de los países capitalistas, radicando la diferencia más notable, según el autor, en que las primeras admitían que no estaban concluidas, sino que se encontraban en un proceso de búsqueda de los esquemas institucionales óptimos para poner en práctica los principios socialistas, mientras que las estructuras capitalistas daban por supuesto haber logrado las instituciones básicas y solo precisarían perfeccionarlas, al igual que había transmitido la propaganda soviética hasta la muerte de Stalin.

La idea de que la democracia socialista era un proceso abierto iba unida a la noción de que solo de modo secundario se realizaba en el derecho. Todas las constituciones de los países socialistas contaban con una declaración de derechos y libertades, semejante a la de los países capitalistas, pero en las primeras el formalismo jurídico se subordinaba a la necesidad social y la protección de los derechos individuales a la garantía de las necesidades colectivas, mientras que en los países capitalistas estarían condicionados por la presión de los grupos de poder. Esta diferenciación impediría, según el autor, poder comparar ambos modelos, careciendo de sentido, hasta que no se socializaran las estructuras capitalistas, utilizar los derechos individuales para evaluar a los países socialistas, ni pensar que dichos países podían adoptarlos sin desvirtuarse.

En efecto, pese a que los críticos de las denominadas democracias populares han insistido en que en ellas el pluralismo político es limitado o en la práctica inexistente. Sus defensores sostienen que en dichos sistemas se desarrolla un proceso electivo desde la base, donde los habitantes se reúnen en consejos para designar a sus representantes. Por otro lado, sostienen que la pertenencia plena a la comunidad política es universal, no está mediada por criterios censitarios; hay mecanismos orgánicos de participación política, mediados por el partido, y el estado se define por un programa de políticas públicas: educación y cultura, sanidad, deportes, etc., orientadas a esa participación en bienes comunes o derechos colectivos universales.

No obstante, llama la atención la destacada atención que Cuadernos prestaba a los modelos de democracias socialistas, después de que tanto la URSS como sus países satélites se hubieran abstenido en la aprobación de la Declaración de 1948, pese a haber colaborado en la redacción del texto y en la de los dos Pactos de 1966, y no ser hasta la conferencia sobre Seguridad y Cooperación en Europa, celebrada en Helsinki, entre 1973 y 1975, cuando dichos países se comprometieran a respetar los principios incorporados en la DUDH, incluidas las libertades individuales ${ }^{46}$.

Ante las dicotomías más arriba señaladas por los colaboradores de Cuadernos entre las democracias capitalistas y socialistas, una serie de autores proponían bien un equilibro entre ambos modelos de democracia, bien la implantación de

46. Para ver con más detalle la postura de la Unión Soviética y de las Democracias Populares respecto de los Derechos Humanos, véase Martín de la Guardia, Ricardo; Pérez Sánchez Guillermo: Derechos Humanos y comunismo. Madrid: Arco Libros, 1999. 
LOS DERECHOS HUMANOS COMO MARCO CULTURAL LEGITIMADOR O MOVILIZADOR

EN EL MESOFRANQUISMO: EL VIGÉSIMO ANIVERSARIO DE LA DUDH EN CUADERNOS...

modelos alternativos a los ya existentes. Ruiz-Giméne ${ }^{47}$ creía que lo ideal sería lograr una democracia integral, que permitiera el desarrollo de la igualdad y de la libertad, al incluir tanto el respeto y la protección jurídica a unas libertades fundamentales como el desarrollo material. Los mayores obstáculos para llegar a ella, según el autor, se encontrarían en el monopolio de los medios de producción por parte de una clase social o un sector de naciones, así como la organización del comercio mundial, denunciando la desigual relación de fuerzas a la que se veían sometidos los países subdesarrollados. Frente a esos monopolios de riqueza o del poder económico que imposibilitaban que la mayoría de la población disfrutara de un mínimo nivel de existencia, Ruiz-Giménez proponía una revisión radical del sentido de la propiedad, tanto a nivel nacional como internacional, apelando a la función social de la misma, como se proponía desde el socialismo democrático y desde el pensamiento cristiano, diferenciándose del significado dado por los marxistas.

Denunciaba del mismo modo D. Joaquín la voluntad de preponderancia de una raza sobre otra, así como el monopolio de las ideas y las creencias, en concreto de las religiosas ${ }^{48}$ y el ejercicio del poder político monopolizado por un grupo que impedía la democracia.

En definitiva, el fundador de Cuadernos reclamaba de forma inequívoca la reforma de las estructuras socioeconómicas y culturales, a fin de que los bienes pudieran ser patrimonio común de todos los hombres, como única interpretación válida de un derecho natural de la propiedad desde la concepción cristiana de la existencia, y una reforma constitucional que transformara la vida política, así como una reforma de las conciencias.

No debe olvidarse que, frente a la definición procedimental de la democracia, como fórmula de selección de dirigentes, existen otras que creen que el carácter representativo de la democracia no depende únicamente del sistema electoral, sino de la capacidad de los gobiernos, libremente elegidos, para identificarse con la voluntad de los electores y/o asegurar el bien común. Desde tales principios es fácil llegar a la reivindicación de la necesidad de avanzar hacia formas más representativas y participativas de la voluntad de los ciudadanos. En este sentido, el Filósofo del Derecho socialdemócrata, García San Miguel ${ }^{49}$, defendía la «sociedad autogestionada", surgida de la búsqueda de un modelo que posibilitara una sociedad igualitaria y libre.

47. Ruiz-Giménez, Joaquín: op. cit.

48. Critica que no se haya podido aprobar en la ONU la Convención sobre Eliminación de Toda Desigualdad Religiosa, por las consecuencias que esa libertad entrañaba en la enseñanza, la predicación, la manifestaciones externas de culto, la fundación de asociaciones, etc. Consideraba, en cambio, que, en España, la Ley sobre el Ejercicio del Derecho Civil de Libertad Religiosa representó un progreso, aunque era preciso seguir trabajando para que desapareciera de ella todo lo que conservaba de discriminatorio y conseguir cuanto antes la independencia total de la Iglesia.

49. San Miguel, Luis G.: "La nueva utopía democrática», Cuadernos para el Diálogo, extraordinario XII, diciembre 1968 , pp. 43-48. 


\section{$110 \quad$ MARÍA DE LA PAZ PANDO BALLESTEROS \\ LOS DERECHOS HUMANOS COMO MARCO CULTURAL LEGITIMADOR O MOVILIZADOR \\ EN EL MESOFRANQUISMO: EL VIGÉSIMO ANIVERSARIO DE LA DUDH EN CUADERNOS...}

García San Miguel informaba cómo los defensores de la denominada «nueva democracia” abogaban por un modelo de organización del poder económico y político que descentralizara las decisiones, manteniendo al mismo tiempo ciertos órganos centrales que aseguraran la cohesión de la sociedad y adoptaran las decisiones aplicables al conjunto de la misma. Responderían a tales principios los sistemas yugoslavo y checoslovaco, organizados a través de un partido, mientras que en occidente eran defendidos por movimientos estudiantiles, como los vinculados al movimiento del mayo del 68.

El autor pese admitir que la autogestión podía funcionar, aunque planteara problemas en la práctica, entendía que, en la teoría, era la fórmula perfecta para crear una sociedad de hombres libres e iguales pues el modelo tenía un sentido democrático profundo que superaba las realizaciones de democratización económica de los países socialistas y de democratización política de los capitalistas. Pese a todas sus insuficiencias, consideraba

Si la teoría política dividía el mundo entre democracias y autocracias, o entre países capitalistas y socialistas, para Roberto $\mathrm{Mesa}^{50}$, uno de los principales expertos internacionales de la Revista, próximo al PCE, el mundo se dividía en países desarrollados y subdesarrollados, al considerar la denominación de países en vías de desarrollo para él no era más que un «eufemismo hipócrita».

Antes de hablar de derechos humanos en los países del Tercer Mundo, el autor consideraba que era necesario que los pueblos alcanzaran su plena libertad política y su total autonomía económica. Por tanto, para los pueblos del Tercer Mundo todos los derechos políticos se reducirían, según Roberto Mesa, al derecho a la autodeterminación, que había de ser conquistado por los oprimidos y nunca concedido por los opresores.

En este sentido, el autor criticaba ferozmente al imperialismo ejercido por los EE. UU. sobre los nuevos Estados salidos de la descolonización y sobre aquellos a los que ofrecía recursos para que lograran el desarrollo, a los que no solo les impedía escoger libremente el sistema de organización política y económica, sino que se les impedía salir del estadio de inferioridad en el que se encontraban. Como resultado, según el autor, de las medidas tendentes a evitar «el contagio socialista».

Solo cuando hubiera desaparecido la presencia extranjera de los países recién descolonizados, cuando se hubiera eliminado la corrupción de las formas de gobierno, cuando hubieran conseguido la propiedad de las fuerzas económicas, habría llegado el momento de la democracia para los países del Tercer Mundo, según el autor.

Como contramodelo a las ideas previamente presentadas, el católico Eduardo Cierco $^{51}$, miembro de Izquierda Democrata Cristiana, IDC, analizaba en el Número

50. MEsA, Roberto: "La democracia y el mundo subdesarrollado», Cuadernos para el Diálogo, extraordinario XII, diciembre 1968, pp. 54-57.

51. Cierco, Eduardo: "La democracia orgánica», Cuadernos para el Diálogo, extraordinario XII, diciembre 1968, pp. 58-60. 
LOS DERECHOS HUMANOS COMO MARCO CULTURAL LEGITIMADOR O MOVILIZADOR

EN EL MESOFRANQUISMO: EL VIGÉSIMO ANIVERSARIO DE LA DUDH EN CUADERNOS...

Extraordinario de Cuadernos, la democracia orgánica, eufemismo al que recurría Franco y el Régimen que encabezaba, para designar al gobierno español ante una Europa que exigía modelos democráticos para formar parte de sus instituciones, y lo hacía desde el punto de vista teórico.

El autor explicaba que en España la teoría de la democracia orgánica se inspiraba en la doctrina tradicionalista aunque mantenían diferencias tales como que los "orgánicos» argumentaban que el partido político era artificial mientras que el municipio, el gremio y la familia eran entidades naturales, mientras que el tradicionalismo estimaba que el ideal comunitario podría impulsar también la sociedad de los años sesenta.

Cierco trataba de desmontar los argumentos de la teoría tradicionalista, inspirada en entidades de representación tradicionales como el burgo, esto es, el municipio medieval, y sus gremios, afirmando que éstos no dejaban de responder a los intereses de unos grupos minoritarios, y constituía grupos de presión protectores del privilegio de unos pocos, mientras que el individualismo moderno del liberalismo generalizaba el ejercicio de la profesión, imponiendo una ley igual para todos. El autor negaba que los órganos de representación medievales, el municipio y la familia pudieran asumir en 1968 las funciones de representación política. Órganos en los que la sedicente democracia, apellidada orgánica por el Régimen franquista, organizaba la representación y a los que criticaba abiertamente.

Si la economía y la cultura estaban ya a la altura de 1968 fundadas en el cambio y no en la autarquía, del mismo modo la representación política, afirmaba Eduardo Cierco, había de organizarse a nivel nacional y no local o gremial. Los partidos políticos surgían de forma natural, continuaba señalando el autor, en una sociedad que era individualista, pluralista y universal al tiempo que se socializaba y se colectivizaba. Reafirmaba estas ideas el tiernista Raúl Morodo ${ }^{52}$ quien aseguraba no entender una sociedad que autodenominándose democrática no garantizase que los ciudadanos puedieran asociarse libremente, esto es, la existencia de partidos políticos, para, a través de ellos, poder conseguir poder político y gobernar. Del mismo modo que no aceptaba tampoco la denominación de democrático para un sistema con un partido único, pese a reconocer que en los países subdesarrollados del Tercer Mundo el pluralismo pudiera ser un obstáculo para su desarrollo y democratización socioeconómica.

Criticaba Morodo que en España se siguiera manteniendo una representación política de carácter corporativo, aunque la LOE hablara de "contraste de pareceres", y pese a que la evolución del Sistema y las tensiones intra-régimen hubieran ido posibilitando informalmente la aparición de distintos grupos políticos.Era esperable que Cuadernos abordara este tema. Desde la presentación de la LOE, 1966, se había reabierto el debate sobre la representatividad del Sistema. Franco la publicitó como una oportunidad de amplia democratización política, aunque añadió

52. Morodo, Raúl: "Grupos políticos y democracia”, Cuadernos para el Diálogo, extraordinario XII, diciembre 1968, pp. 61-62. 


\section{MARÍA DE LA PAZ PANDO BALLESTEROS \\ LOS DERECHOS HUMANOS COMO MARCO CULTURAL LEGITIMADOR O MOVILIZADOR \\ EN EL MESOFRANQUISMO: EL VIGÉSIMO ANIVERSARIO DE LA DUDH EN CUADERNOS...}

verbalmente que los partidos no eran indispensables para constituir una democracia $^{53}$. No obstante, la preparación del Estatuto Orgánico del Movimiento, en el mes de noviembre de 1968, provocaba un animado debate en torno a la probable autorización de asociaciones políticas. En diciembre de 1968 el Consejo Nacional aprobó un proyecto de Estatuto que permitió constituir "asociaciones para el desarrollo de la representación familiar en la vida pública y promover y defender los intereses de la familia». Además el texto establecía que las asociaciones del Movimiento podrían defender los intereses profesionales no representados en la Organización Sindical, un viejo problema nunca resuelto, promocionar la cultura nacional ${ }^{54}$, realizar funciones doctrinales dentro del Movimiento y cualesquiera que llegaran a ser aprobadas por el Consejo Nacional.

Sin embargo, Morodo solo veía tres opciones de cara al futuro: seguir manteniendo la ilegalización de los partidos, hacer evolucionar la doctrina y cambiar el contraste de pareceres por uno de asociaciones, aceptando aquellos grupos que no representaran problemas para el Régimen, o transformar la legalidad y reconocer la existencia de partidos políticos. Siendo esta última opción la que el autor considera más coherente y adecuada. La realidad, en cambio, parecía discurrir por otros derroteros cuando a finales de junio de 1969 se debatió el "Estatuto de Asociaciones", que, pese a las precauciones tomadas para asegurar el control de tales asociaciones, el Régimen no llegó a aprobar.

No podía faltar en una Revista como la que nos ocupa, una reflexión sobre la relación entre Democracia e Iglesia.

Como es sabido, prácticamente a lo largo de todo el s. XIX los Papas reaccionaron, a través de todas las Encíclicas, contra la Democracia y las Declaraciones de Derechos Humanos, principios de raigambre ilustrada, productos de las revoluciones liberales que chocaban con valores inconmovibles del cristianismo. Sin embargo, no faltaron articulistas en Cuadernos, como el democristiano José M. ${ }^{2}$ Vilaseca $^{55}$ o el propio Ruiz-Giménez, que permanecían atentos a las Encíclicas donde se vislumbraban si no cambios sustanciales, al menos signos moderados de avance hacia fórmulas de tolerancia, congratulándose de lo que se consideran el fin de la era constantiniana que había representado la connivencia de la Iglesia con el Estado en busca de privilegios), al tiempo que trataban de exculpar el pasado de la Iglesia, denunciando que era posible extraer de la Doctrina de la Iglesia y del propio Evangelio argumentos para defender las más diversas soluciones políticas, si se las sacaba de contexto y leía parcialmente.

53. Franco Bahamonde, Francisco: Discursos y Mensajes del Jefe de Estado 1964-1967. Madrid: Imprenta del Ministerio de Información y Turismo, 1968, pp. 317-319.

54. González Casanova, José Antonio: "Asociaciones políticas y monarquía moderada", España Perspectiva. Madrid: 1974, pp. 101-122.

55. Vilaseca, José M. ${ }^{a}$ : "La Iglesia y la democracia», Cuadernos para el Diálogo, extraordinario XII, diciembre 1968, pp. 63-66. 
MARÍA DE LA PAZ PANDO BALLESTEROS

LOS DERECHOS HUMANOS COMO MARCO CULTURAL LEGITIMADOR O MOVILIZADOR

EN EL MESOFRANQUISMO: EL VIGÉSIMO ANIVERSARIO DE LA DUDH EN CUADERNOS...

Ruiz-Giménez no se resistía a dejar constancia de la evolución citada en las páginas del monográfico ${ }^{56}$. Recordaba al lector, el fundador de la Revista, que ya en la Encíclica Diuturnum, de León XIII, publicada en 1881, se señalaba que debía realizarse un esfuerzo para armonizar los deberes y derechos de gobernantes y súbditos, marcando límites al ejercicio abusivo del poder político, tanto en lo referido a la libertad de la Iglesia, como a los legítimos intereses de los gobernados, pese a los severos juicios que intercalaba contra el comunismo, el socialismo, el nihilismo, etc. y que en la Inmortale Dei, de 1885, de León XIII (que sintetizaría la doctrina cristiana sobre la construcción de los Estados y la sociedad civil), se incorporaban novedosas orientaciones, manteniendo que la Iglesia no veía que ninguna forma de gobierno "fuera en sí misma reprensible», con tal de que no rechazara la doctrina católica, asegurando que no era digno de censura que el pueblo participara en la gestión de las cosas públicas, así como que la Iglesia no era enemiga de la libertad "buena y legítima», aceptando la tolerancia, si bien seguía apreciándose como "libertad de perdición" aquella encaminada a "despreciar las leyes de Dios".

Sin embargo, la evolución señalada no se había producido de forma lineal. Recuérdese que tras León XIII, Pío X había interrumpido esta progresiva reorientación del colectivo católico hacia los derechos humanos, volviéndose a su censura y sanción, y que fueron muy polémicos los papados de Pío XI y Pío XII. No obstante, el democristiano José M. ${ }^{a}$ Vilaseca, miembro de Izquierda Democratacristiana (IDC) situaba como punto de inflexión en el proceso, el radiomensaje de Pío XII, en la Navidad de 1944, en el que afirmaba que el Pontífice insinuaba el fundamento de la idea democrática de la Iglesia en la defensa de la dignidad de la persona humana.

Pese a todo, la mayor defensa de la democracia por parte de la Iglesia, puede encontrarse en la Pacem in Terris de 1963, de Juan XXIII, que tras reconocer las libertades no solo civiles sino culturales y sociales ${ }^{57}$, proclamadas en las Constituciones, afirmaba que tal doctrina podía conciliarse con cualquier clase de régimen auténticamente democrático. Daba así el paso histórico de asumir todo el elenco de derechos fundamentales contenidos en la Declaración de 1948, avance decisivo que refrendarán tanto el Concilio Vaticano II, como la Gaudium et Spes, la Dignitatis humanae y Pablo VI.

En efecto, la "Constitución pastoral sobre la Iglesia en el mundo actual» del Concilio Vaticano II arrancaba de la dignidad humana para recomendar que los ciudadanos participaran en los asuntos públicos, constatar el anhelo de construir un orden jurídico-político capaz de asegurar una mejor protección de los derechos de la persona, el derecho a usar el sufragio libre para la promoción del

56. Ruiz-GimÉnEZ, Joaquín: op. cit., pp. 9-14.

57. En la vertiente de derechos económicos, sociales y culturales, la Encíclica Rerum Novarum había puesto los fundamentos para la revalorización de los trabajadores al abogar por políticas sociales que favorecieran a oprimidos y marginados propagándose este espíritu a través de las encíclicas sociales y discursos de Pío XI y Pío XII, hasta la Mater et Magistra de Juan XXIII. 


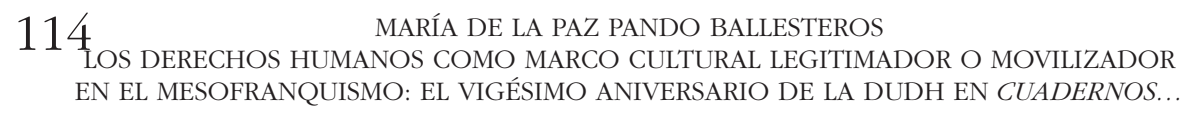

bien común, la exigencia de un estatuto jurídico que estableciera la división de instituciones, al tiempo que rechazaba las formas políticas que ponían trabas a la libertad civil o religiosa y mantenía intacto el principio de indiferencia moral ante la diversidad de regímenes políticos, mientras cumplieran con los principios expuestos, pero reivindicaba su derecho a levantar su vOz siempre que estimara que una situación política los conculcaba. Aplaudía tal proceso Vilaseca, aunque no consideraba oportuno la creación de partidos políticos cristianos o católicos para impulsarlo.

Se reconciliaba así la Iglesia con los ideales de democracia y defensa de los Derechos Humanos inspirados en los principios de Libertad, igualdad y fraternidad de la Revolución francesa, algo trascendente para los promotores de Cuadernos. Recordemos que Ruiz Giménez había calificado de inconsciencia que los Derechos Humanos hubieran nacido fuera de los círculos católicos, ya que la tradición cristiana de fraternidad y solidaridad, en su opinión, tendría que haber propiciado el reconocimiento y promoción de los ideales democráticos ${ }^{58}$. La interiorización de los principios conciliares, junto a la profunda y particular religiosidad personal, y a una preocupación cívica por lo justo y lo público, permitieron a don Joaquín coadyuvar en la modernización del catolicismo español y mostrarlo compatible con los valores democráticos ${ }^{59}$, al tiempo que aprovechaba el incumplimiento de tales principios por el Régimen para denunciar la Dictadura.

\section{Conclusiones}

Cuadernos para el Diálogo mantuvo a lo largo de toda su trayectoria, tanto en su línea editorial como en sus principales artículos de fondo, y especialmente en números monográficos, como el ahora estudiado, una inequívoca defensa de los Derechos Humanos, patrimonio común de demócratas y credo secular apto para creyentes y no creyentes, que funcionaron como coartada o palanca contra el Régimen.

Aprovechando la conmemoración del vigésimo aniversario de la Declaración de 1948, la Revista publicaba un número extraordinario en el que comenzaba por informar a los españoles sobre el contenido y significado de la DUDH, explicando no solo de los principios que recogía y reconocía, sino las carencias con las que contaba. De hecho, los articulistas que participaban en este número pretendían,

58. Gimbernat Ordeig, Juan Antonio: «El pensamiento político y los derechos humanos». En: RuIZ Giménez, Joaquín: El camino hacia la democracia. Madrid: Centro de Estudios Constitucionales, 1985, p. 346.

59. Elías Díaz habla de una evolución del propio Ruiz Giménez desde un iusnaturalismo teológico (clásico o medieval) donde prima la idea del orden, hacia un iusnaturalismo más racional (Ilustración y modernidad) con primacía de los derechos humanos que derivan de la dignidad humana, libertad y solidaridad. En DíAz, Elías: "A pesar del iusnaturalismo». En: VV. AA.: La fuerza del diálogo. Madrid: Alianza, 1997, p. 93. 
MARÍA DE LA PAZ PANDO BALLESTEROS

LOS DERECHOS HUMANOS COMO MARCO CULTURAL LEGITIMADOR O MOVILIZADOR

EN EL MESOFRANQUISMO: EL VIGÉSIMO ANIVERSARIO DE LA DUDH EN CUADERNOS...

que la conmemoración de la Declaración fuera aprovechada, entre otras cosas, para demandar órganos con carácter vinculante frente a las meras recomendaciones de las declaraciones de principios, y a nivel interno para exigir el cumplimiento de aquello que se encontraba reconocido.

Formar a los españoles era una de las funciones de la Revista ${ }^{60}$ para que pudieran exigir al Gobierno una congruencia absoluta en su actitud, de modo que reivindicaran a las Cortes que se ratificaran los Pactos Internacionales, el PIDCP y el PIDESC, y que los pusieran en práctica cumpliendo sus dictados. Importante ejercicio del derecho a la educación no formal en Derechos Humanos, escasamente reconocido.

Por otro lado, una ciudadanía española bien informada podría reflexionar sobre la situación de carencia de derechos y libertades en la que se vivían en el país, Cuadernos prestaba así, un servicio a la sociedad, formando conciencia ciudadana e instando a la población a que utilizara la doctrina de los Derechos Humanos como legitimadora de una actitud contestataria, como instrumento de lucha contra el poder ejercido por la fuerza y al servicio de minorías privilegiadas, y como elemento reivindicativo de nuevos modos de vida, recordando que sus derechos habían ido perfilándose paulatinamente con grandes luchas y sacrificios como única forma de alcanzarlos. Al margen de que se consiguiera o no, se invitaba al lector a la movilización.

La doctrina de los Derechos Humanos se mostraba así como una útil herramienta cultural de la que deducir múltiples exigencias democratizadoras y modernizadoras acordes con la pretensión de una recristianización renovada, como un instrumento versátil, operativo, difícilmente discutible, legitimador o deslegitimador según el caso.

En este sentido, el número de Cuadernos para el Diálogo analizado resulta paradigmático de los debates y los enfoques en torno a la oportunidad que el discurso de los Derechos Humanos, cuyo potencial movilizador empezaba a ser muy evidente, podría ofrecer para combatir la dictadura franquista.

Pero la funcionalidad del discurso de los Derechos Humanos no derivaba sólo de su condición de «marco cultural» potencialmente movilizador. Su utilidad estratégica dimanaba también de la dificultad del Régimen para combatir principios avalados a la sazón por la Iglesia, por los organismos internacionales y teóricamente (aunque no realmente) por el Fuero de los Españoles, como se ha tratado a lo largo de este artículo.

Como era usual, colaboraban en la Revista profesionales, políticos, pensadores de diferentes tendencias. Lo interesante de este número es que, el pluralismo de

60. A esta labor de análisis, información, formación y difusión de los objetivos de la Declaración respondía el que el documentado monográfico incluyera como anexo, el texto de la "Conferencia europea sobre el individuo y el Estado» de octubre de 1968, el Informe Provisional del grupo de trabajo VI: El derecho a la cultura, de la UNESCO, 16-20 septiembre de 1968, así como una actualizada bibliografía relativa a los Derechos Humanos seleccionada por Antonio Truyol. 


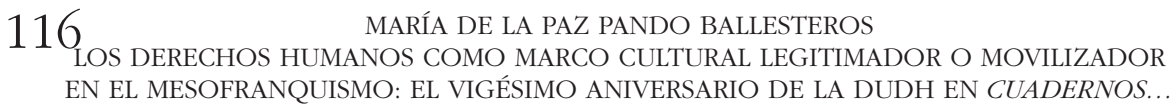

la Revista muestra el debate en torno a cómo debían ser concebidos los derechos de segunda generación, para los liberales derechos de la persona, individuales (aunque el sujeto pasivo sea la sociedad) y para los socialdemócratas y socialistas derechos "colectivos». Esta polémica había estado presente en la discusión de los representantes de los Estados en la celebración de la DUDH, triunfando la visión liberal de los mismos, pues en el texto de la Declaración los derechos de la segunda generación no están definidos como derechos colectivos sino individuales. Debate que Cuadernos lleva a sus páginas.

Los articulistas marxistas, o los más progresistas y preocupados por lo social oscilaban entre la condena de las limitaciones de la DUDH y su celebración como herramienta democratizadora y útil para contrarrestar a la Dictadura. Para ellos no solo era lamentable que no se hubiera logrado un documento vinculante, algo compartido por todos los autores del número, sino también la debilidad en el planteamiento de los derechos de segunda generación cuya exigibilidad quedaba subordinada a los recursos disponibles y cuya implementación gradual y no inmediata era admitida de forma explícita.

Cuadernos reivindicaba la Democracia como único sistema posible en el que podían desarrollarse y garantizarse los Derechos Humanos. A reflexionar sobre el significado y los modelos de la misma dedica el monográfico un amplio espacio en el que incluye un rico debate sobre los modelos de democracia contraponiendo las democracias formales de tipo capitalista con las socialistas, hoy conocidas como populares y su reconciliación en el Estado social.

Como es lógico dado la pluralidad de los autores, estos se dividen entre los defensores ya de un sistema ya de otro, siendo digno de destacar el intento voluntarista de buscar bien modelos intermedios como el de autogestión, bien la de desdibujar las diferencias sin resolver cuál sería el lugar sobre el discurso de los Derechos Humanos de la ONU o la propia Europa sobre el conflicto de la contraposición de modelos.

No faltan artículos que se centran en señalar la insuficiencia de la «democracia orgánica» y de los regímenes de partido único, entre los que se encontraba España.

Por su parte los autores democristianos iban a insistir en modelos de democracia integrada, defendido por ejemplo por Carlos Ollero, que pese a su conservadurismo, defendía el Estado Social y su virtualidad para detener el marxismo.

Sin entrar en el debate sobre los diferentes modelos, Ruiz-Giménez revela su compromiso con las libertades civiles y políticas y el contenido social del que debía dotarse el sistema, apelando para ello a doctrina de la Iglesia.

Para el sector democristiano de la Revista el Concilio Vaticano II representaba una oportunidad para reconciliar a la Iglesia con el Discurso de los Derechos Humanos de la ONU, pasando de este modo la Iglesia defender la democracia. Esto ofrecía además a los cuadernistas la ocasión de abrazarse a la organización internacional e intentar colocar al franquismo contra las cuerdas. 